\title{
BOX 11 | Ocean Acoustic Waveguide Remote Sensing: Visualizing Life Around Seamounts
}

By Nicholas C. Makris, Srinivasan Jagannathan, and Anamaria Ignisca

Collectively, seamounts form a significant biome the size of Europe with important but heavily depleted fisheries (see Box 12 on page 206 of this issue [Etnoyer et al., 2010]). Recently, large seamount tracts have been put aside as protected areas (see Pitcher et al., 2010). Yet, we remain largely ignorant of the dynamics of fish and other nektonic organism movements around seamounts. Hence, there is a pressing need for a survey tool to effectively monitor how stocks respond to management closures, and to determine which fisheries might actually be sustainable.

Ocean acoustics waveguide remote sensing (OAWRS) is such a technique. OAWRS was developed recently for instantaneous imaging and continuous monitoring of fish populations and marine life over continental-shelf-scale areas, covering thousands of square kilometers, at an areal rate tens of thousands to millions of times greater than that of conventional methods. This rate is possible because OAWRS relies on the capacity of the ocean environment to behave as an acoustic waveguide, in which sound propagates over long ranges via trapped modes. With these modes, generated sound waves suffer only cylindrical spreading loss rather than the spherical loss suffered in conventional fishfinding technologies. To form an instantaneous OAWRS image, a vertical source array sends out a short broadband transmission of sound that is omnidirectional in the horizontal (Figure 1). Outgoing sound waves reflect from both the sea surface and seafloor to form vertical standing waves called waveguide modes. These waveguide modes are analogous to the normal modes of a vibrating guitar string, where the entire ocean water column acts like the plucked string. As the waveguide modes propagate, they interact with and scatter from environmental features. Scattered returns from these features are continuously recorded by a horizontally towed line array of receivers (Figure 1) and charted with respect to the receiver array as a function of range (i.e., distance) and bearing (i.e., angle) in the horizontal by temporal matched filtering and planewave beamforming. Typical resolutions are on

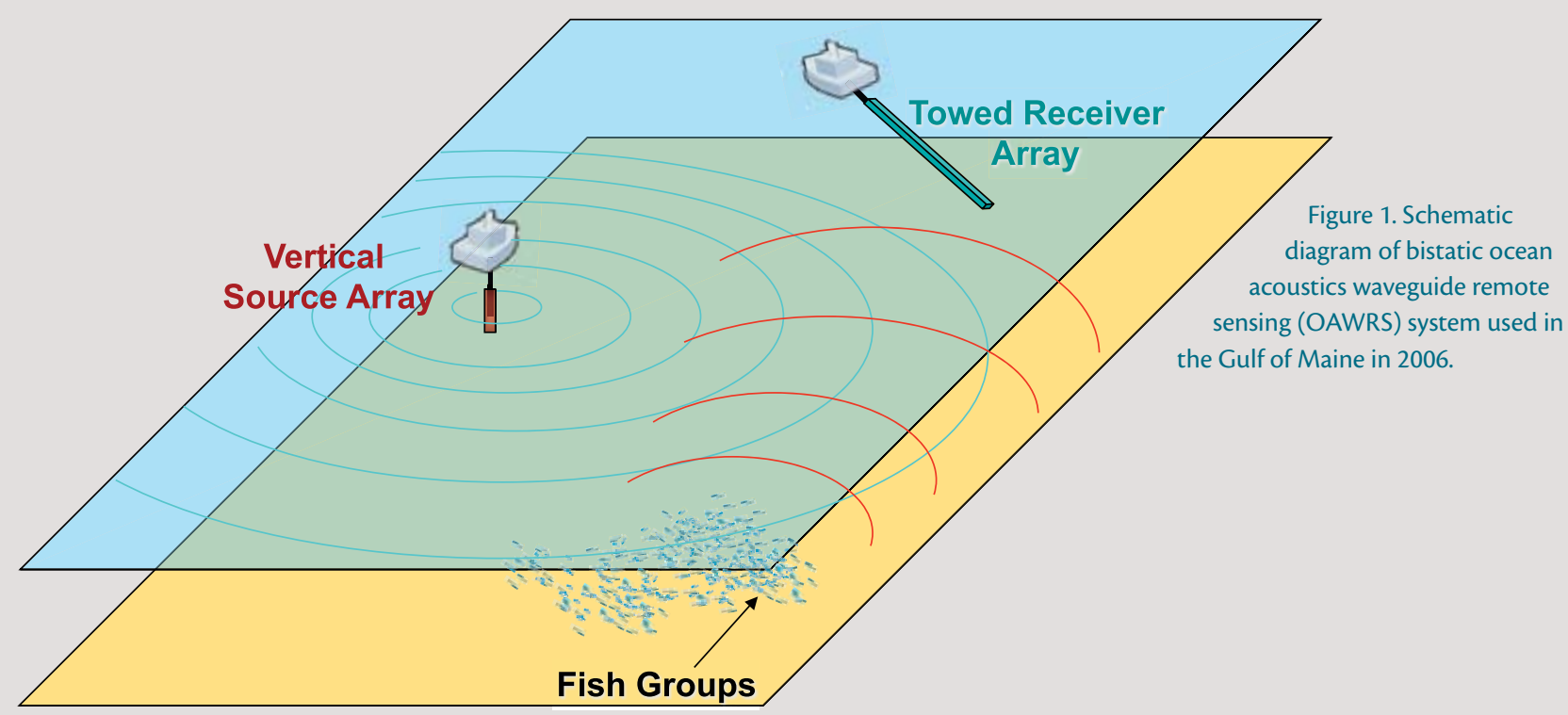

Nicholas C. Makris (makris@mit.edu) is Director, Laboratory for Undersea Remote Sensing, Center for Ocean Engineering, Department of Mechanical Engineering, Massachusetts Institute of Technology, Cambridge, MA, USA. Srinivasan Jagannathan and Anamaria Ignisca are PhD candidates, Department of Engineering, Massachusetts Institute of Technology, Cambridge, MA, USA. 

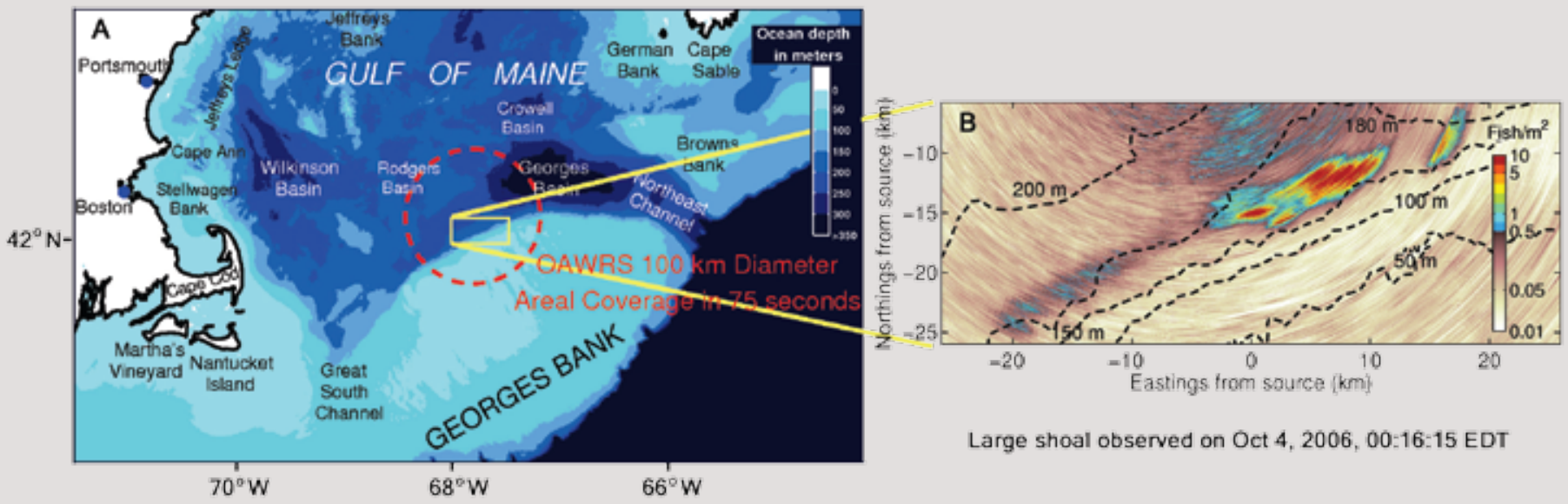

Large shoal observed on Oct 4, 2006, 00:16:15 EDT

Figure 2. OAWRS survey of spawning herring in the Gulf of Maine, fall 2006. (A) Gulf of Maine bathymetry with circle showing OAWRS areal coverage in 75 seconds. (B) Zoom of large herring shoal containing roughly 250 million fish instantaneously imaged by OAWRS in boxed region shown in (A).

the order of tens of meters in range and one degree in bearing. Continuous monitoring with OAWRS produces unaliased, widearea movies of the spatial and temporal distributions of fish populations that can reveal lateral behavioral patterns over tens of thousands of square kilometers (Makris et al., 2006).

The OAWRS technique was used in the Gulf of Maine, on the northern flank of Georges Bank, to instantaneously image vast Atlantic herring (Clupea harengus) shoals during the fall 2006 spawning season (Makris et al., 2009a,b). Each instantaneous OAWRS image surveyed an area $100 \mathrm{~km}$ in diameter every $75 \mathrm{~s}$ (Figure 2A). The herring shoals were observed to form rapidly near sunset for spawning activities, stretch for tens of kilometers, and contain hundreds of millions of herring. The shoal in Figure $2 B$, for example, contains roughly 250 million herring (about 50,000 tonnes, or more than ten times the annual fishing quota).

Seamounts and ridges have previously been visualized using the OAWRS technique (Makris et al., 1995). Although OAWRS has not yet been applied to study marine life around a seamount, the technique shows great potential for providing real-time visualization of fish, krill (Jagannathan et al., 2009), and other nekton in such environments, given its success on the slopes of Georges Bank.

\section{REFERENCES}

Etnoyer, P.J., J. Wood, and T.C. Shirley. 2010. Box 12: How large is a seamount biome? Oceanography 23(1):206-209.

Jagannathan, S., I. Bertsatos, D. Symonds, T. Chen, H.T. Nia, A.D. Jain, M. Andrews, Z. Gong, R. Nero, L. Ngor, and others. 2009. Ocean acoustic waveguide remote sensing (OAWRS) of marine ecosystems. Marine Ecology Progress Series 395:137-160.

Makris, N.C., L.Z. Avelino, and R. Menis. 1995. Deterministic reverberation from ocean ridges. Journal of the Acoustical Society of America 97:3,547-3,574.

Makris, N.C., P. Ratilal, D.T. Symonds, S. Jagannathan, S. Lee, and R.W. Nero. 2006. Fish population and behavior revealed by instantaneous continental shelf-scale imaging. Science 311:660-663.

Makris, N.C., P. Ratilal, S. Jagannathan, Z. Gong, M. Andrews, I. Bertsatos, O.R. Godø, R.W. Nero, and J.M. Jech. 2009a. Critical population density triggers rapid formation of vast oceanic fish shoals. Science 323:1,734-1,737.

Makris, N.C., D.D. Tran, Z. Gong, N. Srikanth, M. Andrews, and P. Ratilal. 2009b. Atlantic herring low frequency target strength estimation from ocean acoustics waveguide remote sensing (OAWRS) data in the Gulf of Maine over 10 days of observation. Journal of the Acoustical Society of America 125(4):2,549-2,549.

Pitcher, T.J., M.R. Clark, T. Morato, and R. Watson. 2010. Seamount fisheries: Do they have a future? Oceanography 23(1):134-144. 